\title{
Evaluation of Adverse Events Following Immunization against Rotavirus Regardless of Recommended Age Restriction
}

\author{
Jesus Reyna-Figueroa1*, Irina Jeanette Bercholc-Urinowsky1, Gabriela Cardoso-Yah', \\ Ricardo Platón Vazquez-Alvarado, Dalila Ramos-López' ${ }^{1}$, Freya Helena Campos-Romero1, \\ Cory Handelsman ${ }^{2}$, Ana Elena Limón-Rojas ${ }^{1}$
}

${ }^{1}$ Central South Hospital, Mexican Oil Company, Petróleos Mexicanos, México City, Mexico

${ }^{2}$ Robert Wood Johnson University Hospital, New Jersey, USA

Email: ^ibercholc@gmail.com, jesus.reynaf@pemex.com

How to cite this paper: Reyna-Figueroa, J., Bercholc-Urinowsky, I.J., Cardoso-Yah, G., Vazquez-Alvarado, R.P., Ramos-López, D., Campos-Romero, F.H., Handelsman, C. and Limón-Rojas, A.E. (2017) Evaluation of Adverse Events Following Immunization against Rotavirus Regardless of Recommend- ed Age Restriction. Journal of Biosciences and Medicines, 5, 78-82.

https://doi.org/10.4236/jbm.2017.58006

Received: June 14, 2017

Accepted: August 14, 2017

Published: August 17, 2017

Copyright ( 2017 by authors and Scientific Research Publishing Inc. This work is licensed under the Creative Commons Attribution International License (CC BY 4.0).

http://creativecommons.org/licenses/by/4.0/

\begin{abstract}
Introduction: Mild and moderate Adverse Events Following Immunization (AEFI) against Rotavirus has not received much attention when the vaccine is administered regardless of recommended age restriction. Objectives: To describe the behavior of mild and moderate AEFI in immunized subjects against Rotavirus, in who age restriction period had not been considered. Methods: A case-control study in which we included immunized patients with monovalent oral vaccine against rotavirus and divided them into two groups: 1) Infants who received RV1 vaccine without considering the recommended period, and 2) Infants who were vaccinated with the recommended schedule. Results: From the total doses, 143/1894 (7.5\%) were administered outside the restriction period. The most frequent AEFIs with the first dose were purpura, polypnea, and rhinorrhea; For the second dose: purpura, bloody stools, irritability and rhinorrhea. Conclusions: This study shows the benefits from vaccination regardless of age restriction are more beneficial compared to the possible risks of AEFI.
\end{abstract}

\section{Keywords}

Rotavirus, Vaccination, Age Restriction, Adverse Reaction

\section{Introduction}

Rotavirus vaccine lowers worldwide mortality against acute diarrheal disease by approximately 50\%, tracking these results over the time [1]. An important part 
for its success was a close follow up from the Adverse Events Following Immunization, were vomit (89.4\%), bloody stools (75.5\%) and abdominal distention $(71.8 \%)$ were the most frequent [2].

Two main concerns for immunizers is vaccination against RV increases AEFI risk, especially intestinal intussusception [3]. Second, nonvaccinated infants are at increased risk of mortality caused by Acute Diarrheic Disease [4]. In order to reduce intestinal intussusception risk, the recommendation for RV immunization should start at 15 weeks of age and it should be completed before 32 weeks of age [5].

Current evidence has shown that the administration period can be extended [6]. Different studies have shown that the benefits of vaccination are greater than the risk of intestinal intussusception [7].

Mild and moderate AEFIs haven't been fully evaluated if the vaccine is administered without considering age restriction.

Our purpose was to describe if vaccinated infants, without taking into consideration age administration, developed AEFIs.

\section{Methods}

We conducted a case control study in which we included those patients who came to Preventive Medicine Department in High Specialty Hospital Mexican Oil Company for the administration of the monovalent oral vaccine against rotavirus (RV1) from 2008-2013. The patients came to the pediatric consult or emergency department up to 54 days after being immunized. We reviewed electronic clinical records to obtain reason of consult, and later we classified the AEFI into "mild" or "moderate" according to literature definitions [8]. We divided patients according to the time of vaccine administration. Group 1 is infants who received RV1 vaccine before 15 weeks of age for the first dose or after 32 weeks of age for second dose. Group 2 is infants who received RV1 vaccine after 15 weeks of age or before 32 weeks of age for the second dose.

The evaluation of the clinical data between groups was performed by the difference of proportions. The numerators were obtained from the population databases from an institutional medical census. The doses of vaccines applied were reviewed from the databases of the Preventive Medicine Service.

\section{Results}

Between 2008 and 2013, 1894 doses of RV1 vaccine were administrated: 1014 for the first dose and 880 for the second dose, resulting in an $86.6 \%$ completion of rotavirus vaccine schedule.

From the total number of the doses, $143(7.5 \%)$ were administrated outside age restriction; 62/143 (43.3\%) for the first dose, and 81/143 (56.6\%) for the second dose.

For the first dose, median age of vaccination was 9.3 weeks (Group 1) versus 16.3 weeks (Group 2). For the second dose, the median was 35 weeks and 27.3 weeks, respectively. 
Table 1. 226 events temporarily associated with RV1 vaccination in children vaccinated out of restraint vs those who were vaccinated in time.

\begin{tabular}{|c|c|c|c|c|c|c|c|c|c|c|}
\hline \multirow[b]{2}{*}{ Variable } & \multicolumn{4}{|c|}{ First dose } & \multirow[b]{2}{*}{$\mathrm{p}$} & \multicolumn{4}{|c|}{ Second dose } & \multirow[b]{2}{*}{$\mathrm{p}$} \\
\hline & $\begin{array}{c}\text { Out of } \\
\text { restriction }\end{array}$ & $\%$ & $\begin{array}{l}\text { Within } \\
\text { restriction }\end{array}$ & $\%$ & & $\begin{array}{l}\text { Out of } \\
\text { restriction }\end{array}$ & $\%$ & $\begin{array}{l}\text { Within } \\
\text { restriction }\end{array}$ & $\%$ & \\
\hline $\begin{array}{l}\text { Abdominal } \\
\text { pain }\end{array}$ & 1 & 16.6 & 15 & 17.6 & $>0.05$ & 1 & 12.5 & 11 & 17.4 & $<0.05$ \\
\hline Vomit & 2 & 33.3 & 24 & 28.2 & $>0.05$ & 2 & 25 & 19 & 30.1 & $>0.05$ \\
\hline Fever & 1 & 16.6 & 18 & 21.1 & $>0.05$ & 2 & 25 & 15 & 23.8 & $>0.05$ \\
\hline Purpura & 1 & 16.6 & 5 & 5.8 & $<0.05$ & 1 & 12.5 & 4 & 6.3 & $<0.05$ \\
\hline Polipnea & 1 & 16.6 & 8 & 9.4 & $<0.05$ & 1 & 12.5 & 6 & 9.5 & $>0.05$ \\
\hline Diarrhea & 1 & 16.6 & 11 & 12.9 & $>0.05$ & 1 & 12.5 & 8 & 12.6 & $>0.05$ \\
\hline Bloody stools & 1 & 16.6 & 2 & 2.35 & $<0.05$ & 1 & 12.5 & 2 & 3.1 & $<0.05$ \\
\hline Irritability & 1 & 16.6 & 14 & 16.4 & $>0.05$ & 2 & 25 & 11 & 17.4 & $<0.05$ \\
\hline Rhinorrhea & 1 & 16.6 & 5 & 5.8 & $<0.05$ & 1 & 12.5 & 4 & 6.3 & $<0.05$ \\
\hline Dehydration & 1 & 16.6 & 11 & 12.9 & $>0.05$ & 1 & 12.5 & 9 & 14.2 & $>0.05$ \\
\hline
\end{tabular}

When we evaluated the 54 day period after vaccination, we found that 6 (0.63\%) of immunized infants from group 2, were hospitalized, in contrast with none of the group 1 . From the second dose, only 4 infants (0.5\%) from group 2 were admitted to the hospital and none of the infants vaccinated in the recommended range. The mean number of consults to the emergency department of pediatrics was similar in both groups and for both doses (8 vs. 8.3 and 8.4 vs. 7.1). Comparing median diarrheic episodes as a reason for consult, there was no significative difference between groups ( 3 vs. 2 and 3 vs. 4 respectively).

The most frequently AEFI found after the first dose were: purpura, polypnea, rhinorrhea; and for the second dose: purpura, bloody stools, irritability and rhinorrhea (see Table 1).

\section{Discussion}

In Mexico, the AEFI surveillance against rotavirus begun in 2007, based on an adapted system to the international recommendations, with the purpose that detection of these events could be useful to the immunizers and other health care workers [9].

Part of this evaluation requires a follow up to monitor for mild and moderate AEFIs. Vaccine resistance among users can create rejection to its administration, disqualifying their validity [10].

In our country it was previously reported that vomiting, bloody stools, fever and dehydration were the most frequent AEFIs [8]. From the point of view of immunization after the recommended period, the results we obtained established, and that when vaccinated after the recommended time with RV1 vaccine, the AEFI percentage is higher than what is being found with the current recommendation, even though the size of the sample was a limitation. Comparing AE- 
FIs at national level, excluding bloody diarrhea, we found that AEFIs were different when administered outside the recommended period. The most frequent AEFIs were purpura, polypnea, rhinorrhea.

These results support that extending the age administration for RV1 vaccination does more good than the risks of its application after the restriction age. In a closed and captive population, such as the Mexican Oil Company health system, age restrictions for the rotavirus vaccine offer a potential incentive for timely vaccination, potentially allowing longer-term benefits beyond the prevention of rotavirus disease. However, the reasons for the delay in vaccination in developing countries are complex and it is not known whether a policy of restricting the first dose of Rotavirus would be a sufficient motivation factor to improve the timeliness of vaccination [11].

The absence of vaccination in children less than one year of age reduces the health benefits of immunization policies substantially. The deaths caused by unapplied intervention can be perceived as a tragedy [12]. For this reason, we should take into consideration the elimination of restrictions on age in rotavirus vaccination. To our knowledge, there is only one research by Patel, et al., where they conducted a model study to estimate the number of deaths that can be prevented with rotavirus immunization, the number of intussusception deaths caused by rotavirus vaccination when administered according to schedule versus an unrestricted schedule up to age 3 years [6]. In that study they estimated that in low and low-middle income countries the restricted schedule would prevent 155,800 rotavirus deaths, in contrast with 203,000 deaths in the unrestricted group; which means that removing the restriction would prevent 47,200 additional rotavirus related deaths in low and low-middle income countries [6].

The importance of performing these evaluations consists in the few possibilities we have to evaluate this population, because it would be unethical to develop a research study in which we left one group unvaccinated according to the vaccine schedule.

Taking in consideration Patel, et al. proposal modeling study, we performed our research study with patients from our health care system, which are a captive population.

\section{Conclusion}

Our analysis suggests that in low- and middle-income countries the additional lives saved by removing age restrictions for rotavirus vaccination would far outnumber the potential excess vaccine-associated intussusception deaths.

\section{Conflict of Interests}

There is no conflict of interest regarding this research.

\section{References}

[1] Richardson, V., Hernandez, J., Quintanar, M., Esparza, M., Johnson, B. and Gomez, C. (2010) Effect of Rotavirus Vaccination on Death from Childhood Diarrhea in 
Mexico. The New England Journal of Medicine, 362, 299-305. https://doi.org/10.1056/NEJMoa0905211

[2] Fernandes, E.G., Leshem, E., Patel, M., Flannery, B., Pellini, A.C., Veras, M.A. and Sato, H.K. (2016) Hospital-Based Surveillance of Intussusception among Infants. Journal de Pediatrics, 92, 181-187. https://doi.org/10.1016/j.jped.2015.06.008

[3] Black, S. (2015) The Costs and Effectiveness of Large Phase III Pre-Licensure Vaccine Clinical Trials. Expert Review of Vaccines, 14, 1543-1548. https://doi.org/10.1586/14760584.2015.1091733

[4] Armah, G., Pringle, K., Enweronu-Laryea, C.C., Ansong, D., Mwenda, J.M., Diamenu, S.K., Narh, C., Lartey, B., Binka, F., Grytdal, S., Patel, M., Parashar, U. and Lopman, B. (2016) Impact and Effectiveness of Monovalent Rotavirus Vaccine against Severe Rotavirus Diarrhea in Ghana. Clinical Infectious Diseases, 62, S200-207. https://doi.org/10.1093/cid/ciw014

[5] WHO (2009) Rotavirus Vaccines: An Update. The Weekly Epidemiological Record, 84, 533-540.

[6] Patel, M.M., Clark, A.D., Sanderson, C.F.B., Tate, J. and Parashar, U.D. (2012) Removing the Age Restrictions for Rotavirus Vaccination: A Benefit-Risk Modeling Analysis. PLOS Medicine, 9, e1001330. https://doi.org/10.1371/journal.pmed.1001330

[7] Reyna, F.J., Vidal, R.P. and Richardson, L.C.V. (2011) Inmunización contra rotavirus con vacuna oral monovalente. Revista de Investigación Clínica, 63, 391-398.

[8] Yen, C., Figueroa, J., Uribe, E., Carmen-Hernández, L., Tate, J., Parashar, U., et al. (2011) Monovalent Rotavirus Vaccine Provides Protection Against an Emerging Fully Heterotypic G9P [4] Rotavirus Strain in Mexico. The Journal of Infectious Diseases, 204, 783-786.

[9] Ndeffo Mbah, M.L., Liu, J., Bauch, C.T., Tekel, Y.I., Medlock, J., et al. (2012) The Impact of Imitation on Vaccination Behavior in Social Contact Networks. PLOS Computational Biology, 8, e1002469. https://doi.org/10.1371/journal.pcbi.1002469

[10] Patel, M.M., Lopez-Collada, V.R., Bulhoes, M.M., De Oliveira, L.H., Bautista, M.A., et al. (2011) Intussusception Risk and Health Benefits of Rotavirus Vaccination in Mexico and Brazil. New England Journal of Medicine, 364, 2283-2292. https://doi.org/10.1056/NEJMoa1012952

[11] Raebel, M.A. and Ou, B.S. (1999) Rotavirus Disease and Its Prevention in Infants and Children. Pharmacotherapy, 19, 1279-1295. https://doi.org/10.1592/phco.19.16.1279.30875

[12] Patel, M.M., Clark, A.D., Glass, R.I., Greenberg, H., Tate, J., et al. (2009) Broadening the Age Restriction for Initiating Rotavirus Vaccination in Regions with High Rotavirus Mortality: Benefits of Mortality Reduction versus Risk of Fatal Intussusception. Vaccine, 27, 2916-2922.

https://doi.org/10.1016/j.vaccine.2009.03.016 
Submit or recommend next manuscript to SCIRP and we will provide best service for you:

Accepting pre-submission inquiries through Email, Facebook, LinkedIn, Twitter, etc. A wide selection of journals (inclusive of 9 subjects, more than 200 journals)

Providing 24-hour high-quality service

User-friendly online submission system

Fair and swift peer-review system

Efficient typesetting and proofreading procedure

Display of the result of downloads and visits, as well as the number of cited articles Maximum dissemination of your research work

Submit your manuscript at: http://papersubmission.scirp.org/

Or contact jbm@scirp.org 